\title{
What we trade at work as employees and how we do it. Using multi-trait multi-method procedure to validate a dual-content approach of employee performance on a Romanian sample
}

\author{
Ruxandra CIULU \\ „AlexandruIoanCuza ${ }^{e e}$ University of Iasi \\ 11, Carol $1{ }^{\text {st }} \mathrm{Blv}$, Iasi, Romania \\ e-mail: ruxandra.ciulu@uaic.ro \\ Andreea NEGRUŢI \\ „AlexandruIoanCuza ${ }^{e e}$ University of Iasi \\ 11, Carol $1^{\text {st }}$ Blv, Iasi, Romania \\ e-mail: andreea.negruti@gmail.com
}

Doi:10.5296/ijhrs.v5i3.8264 URL: http://dx.doi.org/10.5296/ijhrs.v5i3.8264

\begin{abstract}
Globalization and performance management are not new concepts, but they can be approached in new, modern manners in order to identify new trends, new factors of influence on employee performance and, therefore, on organizational performance. In accordance with the current organizational practices and with the need of an empirical validated strategy of performance assessment, the present research aims to present the results of a new standardised assessment approach based on two types of performance and on a multi-sources assessment method. Even though we found no evidence that the type of international management attitude (ethnocentric versus geocentric) would impact the individual in role or extra-role performance levels or that the ERP level of managers would impact the employees ERP levels, we argue that a greater attention should be paid to what we think performance is and how we measure it in an accurate and valid manner.
\end{abstract}

Keywords: Employee, globalization, multi-trait multi-method, multinational, in role performance, extra-role performance 


\section{Introduction}

Globalization is not a new concept and it has been affecting the world for decades (even centuries, some may argue). Globalization of companies, processes, human resources are nowadays realities. Organizations acknowledge thedifficulties associated with social, political, environmental and cultural consequences (Appelbaum et al., 2011). Lucas et al. (2006) outline the distinction between internationalization and globalization in the field of HR. While international HRM is considered to manage ,an international workforce including expatriates, frequent commuters, cross-cultural team members and specialists involved in international knowledge transfere, global HRM involves ,managing international HRM activities through the application of global rule-sets ${ }^{e}$. Regardless of the fact that it has an international, multinational, global, or transnational general strategic position, a multinational is considered to make strategic choices based on economic and political constraints (Dowling et al., 1999).

\section{Performance management and globalization}

Plattsan Sobótka(2010) define individual performance measurement as ,the process that supports the organizational control system by linking the work of each individual employee or manager to the overall mission of the work unit ${ }^{\mathrm{ee}}$. From a managerial perspective, performance is planned based on a shared view of expected performance between the manager and the employee, which relies on a variety of criteria (job description, key accountabilities, performance standards, specific objectives, essential competencies) (Analoui, 2007). In the international context, Dowling et al.(1999) define performance management (PM) as ,a process that enables the multinational to evaluate and continuously improve individual, subsidiary unit and corporate performance, against clearly defined, pre-set goals and targets ${ }^{\text {ee }}$. Claus and Hand (2009) complement Dowlinges definition and refer to PM as ,a fundamental human resource (HR) process that supports the alignment of the global organization $^{\text {ee }}$. Performance in the international environment becomes part of global talent management (GTM)(McDonnell et al., 2010). In one of the few studies on GTM, Stahl et al.(2007) suggest there are a number of practices (e.g., succession planning, leadership development, and PM) which, if utilized effectively, can assist organizations in identifying, developing and retaining key human capital. Bhatti et al. (2011) argue that talent is evaluated through performance, training, human resource development while it has become a strategic weapon and is used as a source of competitive advantage.Also, Darvish and Rezaei (2011) outline the importance of authentic leadership, including the moral and ethical behavior, which should be difficult to alter in adults, as they are value-based, may be shaped by culture and/or family experiences, therefore training could be needed.

There seems to be agreement in the literature that not too many studies have been published on MNCs and international performance appraisal (Appelbaum et al., 2011)or on the PM from global or international perspectives as compared to Western domestic perspectives (Claus and Hand, 2009).

Perlmutter (in Claus and Hand, 2009) was the first to state that international managers ${ }^{\text {ee }}$ attitudes can be grouped into three categories: ethnocentric, polycentric and geocentric. The 
fourth category (regiocentric) was added later as an intermediate stage between polycentric and geocentric approach. The ethnocentric approach is usually perceived as the first step in the international development of any company, though some companies maintain this approach in advanced stages of internationalization. In any subsidiary, key positions are filled by managers from the company country of origin, while local employees can only evolve up to middle management and some less important management positions. Also, local employees can never be transferred to fill positions in the country of origin. The geocentric approach is considered to be the ultimate stage for a company, as nationality becomes irrelevant and only the value of the employee is important. All positions worldwide are open to all employees at international level. A number of reviews of international HRM have stressed the need to move beyond the ethnocentric centralization of a global firm 's domestic point of origin and learn to discern and incorporate the institutional, cultural and historical factors that vary across regions and nations (Engle et al., 2007).

There is a dilemma regarding HR activities in the international context: „can we manage our people like a global product?ee (Dowling et al., 1999). Some argue that standardizing work practices and HRM activities is not the same as product standardization and that globalization occurs at the level of the particular function. Another challenge involves the activities that can be delegated from the head office to the subsidiary HR managers. The level highly depends on type of approach (ethnocentric, polycentric, geocentric, regiocentric), as well as on the need for control from the head office (e.g. a geocentric approach to staffing requires standardized policies to encourage equal treatment to all staff on international assignments) (Dowling et al., 1999).

Several studies addressed the issue of expatriate performance. According to Lucas et al.(2006), MNC's PM practices are a mix of home and local systems and concepts, which are also affected by contextual factors of the host country (country culture, economic, political and legal systems) and organization-specific factors (strategy, structure and culture and country of origin). Dowling et al.(2008) consider that in evaluating expatriate performance it is important to consider the impact of some variables (see Figure 1).

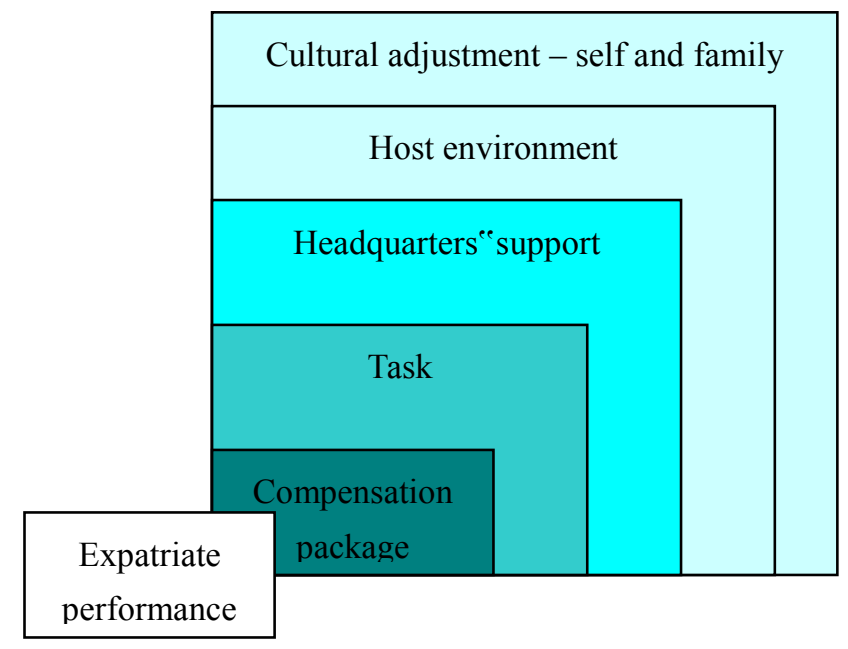

Figure 1 - Variables affecting expatriate performance (Source: Dowling et al., 2008) 
Claus and Hand (2009) developed a model of customization of the PM system in an MNC that includes three indepedent variables (cultural distance between headquarters and subsidiaries; upstream and downstream PM processes; and the strategy of internationalization - global integration vs. local responsiveness), as well as one controlling variable (enterprise conditions - size, industry, sector).

The dependent variable identified by Claus and Hand is the degree of customization (standardization, glocalization, localization). The research database they created is comprised of the responses 97 different organizations (headquartered in 13 different countries), 53 from Bulgaria and 44 from Romania. Their findings indicate that MNCs do not necessarily aim to standardize their PM system, as they either standardize, glocalize or localize it. Therefore, they either dictate the corporate HQ PM system to their subsidiaries, allow subsidiaries to use an autonomous PM system that fits their local needs, or facilitate the development of a hybrid or glocalized system.

In the case of globally integrated companies (versus local responsiveness), there is a greater tendency to use a standardized PM system. Claus \& Hand concluded that ,the transferability of a Western PM system (operating in a context of relatively low power distance and masculinity) is problematic and that the PM system may need to be customized for cultures that accept difference in power, and where gender roles are very specifice. In the case of expatriate assessment, a standardized treatment is necessary, also due to the fact that, in HR literature, it is agreed that using the same performance assessment (PA) instrument is preferable for equity and comparability purposes.

Scullion and Starkley's study (2000) on 30 British-owned international companies resulted into three categories of companies: centralized HR companies, decentralized HR companies and transition HR companies. Only companies in the first category (centralized HR companies) define PM globally, which would correspond to a geocentric approach of the company. Interestingly, the general agreement in literature is that companies with an ethnocentric approach also centralize HR activities based on their need for control and, most of the times, lack of experience in the international environment.

Generally, employees are appraised by their immediate superior, but this can be problematic in the case of country managers or CEOs as their immediate superior is not located in the country where they are assigned; for the other employees, appraisal is usually conducted by the CEO (Dowling et al., 2008). In the case of international projects or short term expatriations, a person from the head office is usually in charge of conducting the appraisal process. Also, even though organisations may have a well-designed and articulate strategy for staffing their foreign operations, Collings et al.(2007) argue that they have often failed to monitor the performance of international assignees to accurately measure their performance and contribution to the organization. These can be due to long distance assessments, trust between the appraiser and the appraisee, lack of body language evaluation (Appelbaum et al., 2011), communication issues (Suutari and Tahvanainen, 2002 in Lucas et al., 2006), as well as problems related to specificity and measurability when translating goals (hard, soft and contextual) into performance appraisal criteria (Dowling et al., 2008). 
Appelbaum et al.'s study (2011) revealed that MNCs tend to use formal or informal multi-rater systems. As part of such system, face-to-face appraisal evaluation is preferable, but sometimes difficult to perform when the superior and the subordinate are situated at significant distance. Some of the managers they questionned felt that that it is necessary to also add self-appraisal in order to provide more information, but this is considered to be labor intensive. And although appraisal methods - such as the 360 degree - is of great value, some cultures (e.g. collectivist cultures) do not accept such methods.

\section{Current Study}

In accordance with the current organizational practices and with the need of an empirical validated strategy of performance assessment, the present research aims to present the results of a new standardised assessment approach based on two types of performance and on a multi-sources assessment method.

For the current paper we formulated two main objectives:

1. The first research objective was to validate a dual-content approach of employees ${ }^{\text {ee }}$ job performance, namely in role performance and extra-role performance, on a Romanian sample;

2. Secondly, we aimed to test whetherinternational managerse attitudes (ethnocentric, polycentric, regiocentric and geocentric) influence employees performance.

\subsection{Dual-content of job performance}

Previous studies (MacKenzie, S.B., Podsakoff, P.M., and Fetter, R., 1993; Ţuţu, 2012; Ţuţu and Ciulu, 2011) have already proposed a dual-approach of employees job performance, while other authors still promote the idea of one type of job performance with many determinants (Cambell et al., 1993).

Firstly, let us define the job performance: to understand the dual content of job performance lets imagine a coin. Even if the two faces are opposite and with an independent space from one another, they are irreversibly linked. In a similar way, we see job performance as a dual-content concept formed by in role performance, on one hand, and by extra-role performance, on the other hand. As we agree with Campbell's behavioural definition of performance (Cambell et al., 1993), we believe that performance is not the result of the action, but the action/behavior itself. So, if performance is a choreography of behaviors, why not analyse the hole set of individual behaviors at work? Why not analyze the formal expected behavior (in role performance), which is linked with the job requirements and objectives and with the individual competences and values, together with the extra-role performance, the behavior which is often informal requested, and translated as behavioral expectancies from our employees. Extra-role performance dimensions were often called organizational citizenship behaviors(Bateman and Organ, 1983),prosocial organizational behaviors(Brief and Motowidlo, 1986), or extra-role behaviors(Van Dyne et al., 1995). Other approaches (Vasconselos, 2013) enlarge this view to the values area and include spirituality in the workplace, as basis element for four categories of organizational aspects which impact the 
job outcomes: organizational climate, organizational culture, mystical resources and structural (decent work conditions).From our point of view, extra-role performance is a composite concept, including all elements above (except spirituality and its related aspects), and persistence, sportsmanship and prosocial behavior toward organization and others (e.g.: colleagues, clients, public), manifested by agent/employee of a specific organization. Extra-role performance is also directly linked to team behaviour, which in turn can be influenced by the compensation system and the job design, autonomy especially (Godeanu, 2012). Often the results of these extra-role performant behaviors are rather seen translated in the team performance, as employee might exit their formal professional job in order to provide support in the professional area of the employee he/she is helping prosocially and proactively.

In terms of trading, we think that employees have two behavioral sets they bring and trade at work, in relationship with the performance. One set is highly formal, and dependent on the organizational rules while the second one is informal and strongly connected with the individual rules, personal values and motivations. For example, being a productive employee is a formal request of my employer, while being a prosocial employee is more a matter of personal choice to behave in a certain way. As we see these behavioral sets deeply connected, the first purpose of this paper was to empirically validate a dual-content performance assessment on a Romanian sample, while the second one was to analyse if the international managers ${ }^{\text {ee } a t t i t u d e s ~ d o ~ i m p a c t ~ t h e s e ~ t w o ~ c o n t e n t s ~ o f ~ j o b ~ p e r f o r m a n c e . ~}$

\subsection{Methods}

The research strategy involved a two-phase analysis. In the first phase we validated our instruments measuring a dual-content job performance using a Multi-Method Multi-Traits approach (MMTM).In the second phase were tested the following research hypotheses:

Hypothesis 1: The type of international managerse attitude has a strong influence over employees ${ }^{\mathrm{ec}}$ in role and extra-role performance.

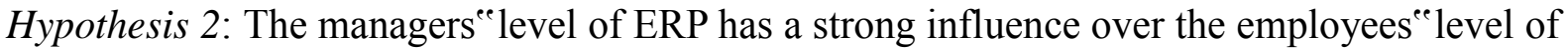
ERP.

\subsubsection{Sample}

The employees ${ }^{\text {ee }}$ groups of eight Romanian based companies were invited to participate in the study. The final sample comprised a number of 298 employees. The participation rate was $82.6 \%$, and the mean of age was 30 . Base on field of activity, 75 employees were from IT\&C sector, working in companies with geocentric approach, while the rest of the subjects were employed in ethnocentric orientated companies from sales or production fields.

\subsubsection{Procedure}

Letters of invitations were sent to all participants by e-mail. The invitation included a brief study explanation and a description of the associated benefits for participants and for the companies. The research was strongly endorsed by management. The research strategy used involved a multi-source assessment. For all employees there were collected ratings for in role 
and extra-role performance, assessed from three sources (boss, peer, self).

\subsubsection{Measures}

For the measurements of in role and extra-role performance two instruments were used: Robertson's performance scale (Robertson et al., 1999; Robertson et al., 2000), and Smith's extra-role performance scale (1983). Robertson's performance scale offers a global score for the individual formal job performance. It is easy to use, with 3 minutes completion time. It has six items (e.g.: "He/she achieves all job objectives"). The assessor is asked to rank on a five-point scale the level of agreement/disagreement regarding all the behaviors stated by the items (1-totally disagreement, 5-totally agreement). The general score can be calculated and used either as sum or mean. Extra-role performance scale has 16 items (e.g.: "He/she helps other employees while they are absent", "He/she doesn't take undeserved pauses") and a five-point scoring scale. The high scores are associated with a high extra-role performance level, while the low ones are associated with lower levels of extra-role performance.

\subsection{Results}

Before using the dates to test our research hypotheses, we aimed to validate the two instruments used in the multi-source assessment context. Thus, there were two phases of this process: (1) in the first one, there was verified the internal consistency of both scales, while (2) in the second phase we used the procedure multi-methods multi-traits in SEM to analyze and confirm the factorial structure of data. The purpose of the second phase was to validate the multi-source and dual-content assessment.

Table 1 presents the alpha Cronbach indices for both scales, for all assessment sources. The values obtained (above value .90) suggest that both instruments have a high degree of internal consistency.

Table 1. Internal consistency indices

\begin{tabular}{lll} 
Measurement & $\begin{array}{l}\text { Source } \\
\text { ratings }\end{array}$ & of \\
\hline $\begin{array}{l}\text { In role performance } \\
\text { (Robertson, 1999, 2000) }\end{array}$ & peer & 0.97 \\
& self & 0.96 \\
\hline $\begin{array}{l}\text { Extra-role performance scale } \\
\text { (Smith, 1983) }\end{array}$ & boss & 0.94 \\
\hline & peer & 0.96 \\
& self & 0.95 \\
\hline
\end{tabular}




\section{Macrothink}

International Journal of Human Resource Studies

ISSN 2162-3058

2015, Vol. 5, No. 3

The aim of the second phase was to identify, with the help of structural equation modeling (SEM), which is the model which best describes our empirical data. For this analysis we used multi-methods multi-traits approach in SEM [3]. Three reasons counted when MMTM procedure was chosen:

1. It is the most appropriate method to validate a multi-source assessments (270 or 360 degrees assessment), in organizational environment;

2. The validation procedure takes into account all items of all scales, and not the final/general score obtained. Moreover, in the analysis were included all items rated from three sources (boss, peer, self);

3. We wanted to have a strong validation procedure for the two concepts used (in role and extra-role performance), which takes into account both the content of assessment and the source of ratings.

There were four models which were proposed for testing. The model fit was analyzed by taking into account the following model fit indices. These were: $\chi 2(\mathrm{df}), \mathrm{GFI}, \mathrm{NFI}, \mathrm{TLI}, \mathrm{CFI}$, and RMSEA. The ideal references values are above .95 for GFI, NFI, TLI and CFI (and minimum of .80), and maximum of .08 for RMSEA [17]. Those four alternative models were:

1. Model 1 with two factors - it is based on the premisis that there are no differences due to the rating sources (boss, peer, self), the content assessed being important (in role versus extra-role performance).

2. Model 2 with three factors - is based on the idea that those three ratings sources are important, while the type of content could be ignored.

3. Model 3 proposed a six factors (performance sub-dimensions) model. Those factors are: in role performance assessed by manager, in role performance assessed by peer, in role performance assessed by self, extra-role performance assessed by manager, extra-role performance assessed by peer, extra-role performance assessed by self.

4. Finaly, the fourth model (Figure2) proposed a five factors structure, with two content types (in role and extra-role performance) and three ratings sources (boss, peer, self).

The analysis showed that the first three models proved to be inadequated. Table 2 shows the model fit indices obtained. 
Table 2. Model fit indices for model 1, 2, and 3

\begin{tabular}{lllllll} 
Modl fit indices & $\chi 2(d f)$ & GFI & TLI & NFI & CFI & RMSEA \\
\hline Model 1 & $8588.602(2078)$ & 0.35 & 0.71 & 0.66 & 0.72 & 0.10 \\
& & & & & & \\
\hline Model 2 & $5188.238(2003)$ & 0.62 & 0.85 & 0.79 & 0.86 & 0.07 \\
& & & & & & \\
Model 3 & $7399.699(2064)$ & 0.39 & 0.76 & 0.71 & 0.77 & 0.09 \\
\hline
\end{tabular}

The forth model (Figure 2) obtained the most adequate model fit indices $(\chi 2(2003)=$ 5188.238; $\mathrm{p}=.000 ; \mathrm{GFI}=0.62 ; \mathrm{TLI}=0.85 ; \mathrm{NFI}=0.79 ; \mathrm{CFI}=0.86 ; \mathrm{RMSEA}=0.07)$, confirming the five factors structure. Even though the indicese values are not ideal, these results confirm the fact that the both scale used are adequate in therms of dual-content and ratings sources, and are highly appropriate for use in real organizational settings.

In the second phase of our research we tested the two hypotheses. We found no evidence to support these hypotheses on the ideas that the type of international management attitude (ethnocentric versus geocentric) would impact the individual in role or extra-role performance levels. Further, we found no evidence that the ERP level of managers would impact the employees ERP levels. For the second hypothesys we admit the limit in terms of small sample of managers and we do think that these results were impacted by the biased ratio between the number of managers and the number of employees assessed.

\section{Discussion}

The importance of validated measured in organizations is well-known and highly promoted in the literature. The main finding of the present study consists in the five factors structure of performance assessment. The utility of such an assessment based on a dual-content of performance and on a multi-source approach could translate into HR processes such as recruitment and selection, training strategies, development and talent management policies, and so on. In a few words, the results of a valid assessment process, especially in the case of performance, could bring a clearer image in terms of current human capital and needed human resources, and could have the potential to shape a great range of organizational processes.

From both the individual and organizational point of view, we think that it is crucial to analyse what employees bring to work in terms of productive behavior, be it formal or informal. How employees do the trade between performance delivered and incentives is a well-known issue. Multinational companies generally adopt performance assessment systems that more or less reflect the system in the country of origin. As MNCs develop internationally, they tend to move from an ethnocentric to a geocentric approach and their performance 
assessment systems evolve. Even though the hypotheses in this study are not confirmed, we believe that the differences between the performance assessment systems in different types of multinational companies (grouped by type of multinational, type of industry, number of employees, regional or international expansion and so on) should be further researched. We also believe that our findings could bring strong evidence that the professional behaviors at work could be better understood as personal choice of manifestation, and future research should focus on investigating the motivating and priorities aspects behind the performance behaviors. Moreover, we consider this validating study the first step to a better understanding of the performance management process in Romanian settings. The evidence at the individual level, in terms of job performance,s dual-content and formal and informal sets of behaviors manifested at work, could represent the base of a more general research strategy meant to link the individual input and output with the organizational performance, all that integrated in a general framework of performance management system dependent on globalization and management strategies. Despite the limits of this research (e.g.: limited sample of subjects, $\mathrm{N}=298$ ), we think that the results of our confirmatory factorial analysis show us that greater attention should be paid to what we think performance is and how we measure it in an accurate manner. If informal driven extra-rolbehaviors could boost the team performance, for sure the lack of (some of) them could also have a reverse impact. The literature promotes these negative extra-role behaviors toward team, organization, job or professional resources in terms of counterproductive behaviors. These are often linked with non-ethical aspects and criticism of management, often challenging authority (Negruti, 2014).

On the other hand, the lack of evidence that the type of international management attitude (ethnocentric versus geocentric) would impact the individual in role or extra-role performance levels, could reinforce the idea that extra-role performant behaviors are manifested more as a personal choice, than as a behavior aligned with organizational directions or its social rules. We intend to test in future research the influence of human values and leadership style over extra-role performance, as we beleive that this choosing behavior is linked also to other individual and organizational factors (e.g.: internal motivators toward job and career, job satisfaction, perceived authority level, so on).

As future directions of research we also intend to test the obtained factorial structure on a more large sample of employees, by taking also into account other basic individual aspects (e.g.: human values) which could have the potentiality to predict a wide range of human behaviors, including choice behaviors job-related (as the extra-role ones are). 


\section{Macrothink}

Figure 2.Structural equation testing the alternative multivariate model, with two types of content (in role and extra-role performance) and three ratings sources (boss, peer, self)

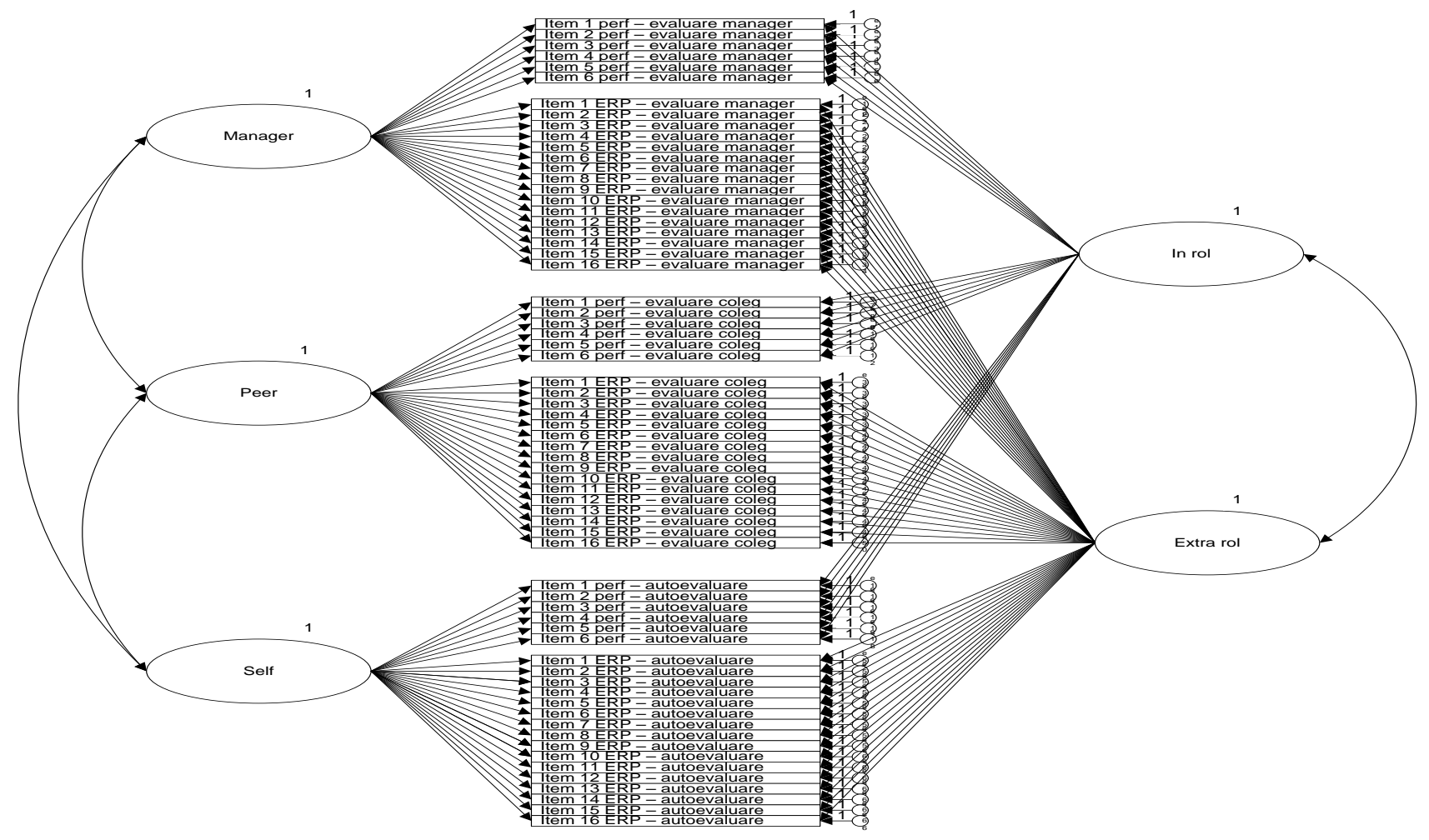

\section{References}

[1] Analoui, F. (2007): Strategic Human Resource Management, Thomson Learning, London

[2] Appelbaum, S.H., M. Roy, T. Gilliland (2011): Globalization of performance appraisals: theory and applications, Management Decision, Vol. 49 Iss: 4 pp. $570-585$

[3] Balazsi, R. (2008). Procedura multi trasatura multi metoda: o abordare din perspectiva SEM, Psihologia Resurselor Umane, 6(2), 106-111.

[4] Bateman, T.S., \& Organ, D.W. (1983). Job satisfaction and the good soldier: the relationship between affect and employee citizenship. Academy of Management Journal, 26, 587-595.

[5] Brief, A.P., \& Motowidlo, S.J. (1986). Prosocial organizational behavior. Academy of Management Review, 11, 710-725.

[6] Campbell, J.P., McCloy, R.A., Oppler, S.H., \& Sager, C.E. (1993). A theory of performance. In Schmitt, N., Bormann, W.C. et al. (Eds.), Personnel selection in organizations, 35-70, San Francisco, Jossey-Bass.

[7] Claus, L., M.L. Hand (2009): Customization Decisions Regarding Performance Management Systems of Multinational Companies An Empirical View of Eastern European 
Firms, Vol 9(2): 237-258

[8] Collings, D.G., H. Scullion, M.J. Morley (2007): Changing patterns of global staffing in the multinational enterprise: Challenges to the conventional expatriate assignment and emerging alternatives, Journal of World Business 42, p. 198-213

[9] Dowling, P., M. Festing, A.D. Engle (2008): International Human Resource Management, 5th ed., South-Western CENGAGE Learning EMEA

[10] Dowling, P.J., D.E. Welch, R.S. Schuler (1999): International Human Resource Management: Managing People in a Multinational Context, South-Western College Publishing

[11] Engle, Sr., A.D., P.J. Dowling, M.E. Mendenhall (2007): Transnational Trajectories: Emergent Strategies of Globalization and a New Context for Strategic HRM in MNEs, International HRM Conference, June 2007

[12] Lucas, R., B. Lupton, H. Mathieson (2006): Human Resource Management in an International Context, Chartered Institute of Personnel and Development

[13] MacKenzie, S.B., Podsakoff, P.M., \& Fetter, R. (1993). The impact of organizational citizenship behavior on evaluations of salespersons se performance. Journal of Marketing, 57, 70-80

[14] McDonnell, A., R. Lamare, P. Gunnigle, J. Lavelle (2010): Developing tomorrow's leaders - Evidence of global talent management in multinational enterprises, Journal of World Business 45, p. 150-160

[15] Negruți, A. (2014). Investigating the theoretical framework for ethics behind managerial innovation. 3rd European Conference on Narrative Therapy and Community Work, Iasi, Romania $2.07-4.07,2014$

[14] Platts, K.W., M. Sobótka(2010): When the uncountable counts: An alternative to monitoring employee performance, Business Horizons, No. 53, p. 349-357

[15] Robertson, I.T., Gibbons, P., Baron, H., MacIver, R., \&Nyfield, G. (1999). Understanding management performance. British Journal of Management, 10, 5-12.

[16] Robertson, I.T., Baron, H., Gibbons, P., MacIver, R., \&Nyfield, G. (2000). Conscientiousness and managerial performance.Journal of Occupational and Organizational Psychology, 73, 171-180.

[17] Schreiber, J.B., Stage, F.K., King, J., Nora, A., \& Barlow, E. (2006). Reporting Structural Equation Modeling and Confirmatory Factor Analysis Results: A Review.

[18] Scullion, H., K. Starkley (2000): In Search of the Changing Role of the Corporate Human Resource Function in the International Firm, International Journal of Human Resource Management, Vol. 11, No. 6 (2000), p. 1061-81.

[19] Smith, C.A., Organ, D.W., \& Near, J.P. (1983). Organizational citizenship behavior: its 


\section{Macrothink \\ International Journal of Human Resource Studies \\ ISSN 2162-3058 2015, Vol. 5, No. 3}

nature and antecedents. Journal of Applied Psychology, 68, 653-663.

[20] Stahl, G. K., Bjorkman, I., Farndale, E., Morris, S. S., Stiles, P., \& Trevor, J., et al. (2007): Global talent management: How leading multinationals build and sustain their talent pipeline. Faculty \& Research Working Paper. Fontainebleau, France: INSEAD.

[21] Tutu, A. (2012). Is competency enough? Understanding job performance in an economic depression context, International Journal of Learning and Development, 2(1), 320-329.

[22] Tutu, A., Ciulu, R. (2011). Strategic approach of employee performance.An interdisciplinary overview, Business Excellence, 2, 260-263.

[23] Van Dyne, L., Cummings, L.L., \& Parks, J.M. (1995).Extra-role behaviors.Research in Organizational Behavior, 17, 215-285. 